\title{
GLOBAL DERIVATIVES Products, Theory and Practice
}


This page intentionally left blank 



\section{Published by}

World Scientific Publishing Co. Pte. Ltd.

5 Toh Tuck Link, Singapore 596224

USA office: 27 Warren Street, Suite 401-402, Hackensack, NJ 07601

UK office: 57 Shelton Street, Covent Garden, London WC2H 9HE

\section{British Library Cataloguing-in-Publication Data}

A catalogue record for this book is available from the British Library.

\section{GLOBAL DERIVATIVES: PRODUCTS, THEORY AND PRACTICE}

Copyright (C) 2007 by World Scientific Publishing Co. Pte. Ltd.

All rights reserved. This book, or parts thereof, may not be reproduced in any form or by any means, electronic or mechanical, including photocopying, recording or any information storage and retrieval system now known or to be invented, without written permission from the Publisher.

For photocopying of material in this volume, please pay a copying fee through the Copyright Clearance Center, Inc., 222 Rosewood Drive, Danvers, MA 01923, USA. In this case permission to photocopy is not required from the publisher.

ISBN-13 978-981-256-689-8

ISBN-10 981-256-689-9

Typeset by Stallion Press

Email: enquiries@stallionpress.com

Printed in Singapore. 


\section{PREFACE}

The innovation in financial derivatives over the past 20 years is historically unprecedented in its scope and speed. Callable spread options, constant proportion portfolio insurance (CPPI), target redemption notes (TARN), callable snowballs, thunderballs, collaterized debt obligation (CDO) squared, himalaya, podium, galaxy, just to name a few among the more exotic products have now become ordinary. Along the same lines, new accounting standards have urged for a better comprehension of the use and risk management of financial derivatives. And the increase of computing power has also pushed to price more accurately financial derivatives with more advanced mathematical and computational tools.

In Global Derivatives: Products, Theory and Practice, the authors aim to provide a comprehensive introduction to the subject from a practitioner point of view with only the minimum necessary quantitative developments. All the authors are experienced financial engineers. Most of them are working for Pricing Partners and have practised cutting edge and innovative technological developments, in order to remain in "best practice". Much has already been written on derivatives in many text books. What differentiates Global Derivatives from the other books on the subject is that it provides details on products, models and pricing tricks that are used in banks and often not mentioned in the academic books.

This book is designed as a graduate textbook for financial engineering course. Student should find a practitioner point of view on 
the subject that could be very useful when considering a carrier in derivatives either as a quant, a trader or a structurer. This book should also appeal to practitioners, to the end users of derivatives, that is, corporate treasurers, portfolio managers, hedge funds concerned by hedging financial risks or looking for investment strategies that fit their risk appetite in a given market environment such as low interest rates and low volatility.

The first two chapters are a gentle introduction to derivatives products and markets. It explains the vanilla products such as forwards, futures, standard call and put options and their use in hedging risk. The basic option strategies are also considered.

The third chapter is about the philosophy of modeling with consideration about pricing and hedging fundamentals for fixed income products, and specific considerations for exotic and hybrid structures. In particular, Chapter 3 tries to give an insight into the models people use to price or hedge and why they make this choice. It emphasizes that the quality of a model should not only be measured in terms of pricing but also hedging. In addition, it is stressed that calibration is the art of pricing and should be closely reviewed in the pricing methodology. Before discussing more advanced pricing models, Chapter 4 provides a presentation to the seminal Black-Scholes model and its underlying hedging strategy.

Then in Chapter 5, the reader will find a description of the foundation of the fixed income derivatives market, with a description on curve bootstrapping techniques, LIBOR-in-arrears swaps, constant maturity swaps (CMS) with replication method, interest rate swaps, cross currency swaps as well as vanilla interest rate options such as caps and floors and European swaptions. Leveraging on these simple products, Chapter 6 discusses the most common models to handle the smile, that is, jump models, local volatility models and stochastic volatility models, in particular the SABR model that we are using extensively in investment banks.

Chapter 7 reviews the classic term structure models with the short-term rate models (Vasicek, Hull and White, CIR and Black and Karasinski) and the market models, especially the LIBOR market model of Brace, Gatarek and Musiela (BGM) which is very popular 
among practitioners given its ability to reproduce market prices for caps, floors or swaptions when using Black's formula.

Chapter 8 is a detailed introduction to the growing market of inflation derivatives. It gives a description on the main street inflation structures such as year-on-year swaps, inflation bonds and zero-coupon swaps, and the recent market for caps and floors and swaptions. This chapter also gives a detailed account of pricing issues, such as the incorporation of seasonality, which are based on the original work of some of the authors of this book.

Chapter 9 tackles the rising and promising sector of hybrids. In particular, the reader will find a long discussion about power reverse dual currency (PRDC) that have been very popular in Japan. Chapter 10 provides an extensive overview of the latest innovative financial derivatives like callable snowballs and target redemption notes (TARN).

The book finishes with a chapter (Chapter 11) on the latest technologies developed by Pricing Partners. As the key to success in the derivatives business is financial innovation, it has become very relevant to build generic system where the end user can easily develop customized products and the corresponding pricing tools. This chapter describes the type of architecture which allows this flexibility, referred to as generic pricer. More precisely, a generic pricer is a tool that allows the description of any payoff without any new programming development. Once the payoff has been specified, the system assembles the algorithm to solve the pricing model. This is a very powerful architecture that can generate a first mover advantage to the most innovative institutions.

Last but not the least, in the appendix sections, the reader will first find a technical review of stochastic calculus and risk neutral pricing which is central to the pricing and hedging of derivatives transactions. While Appendix A is a rigorous presentation of the fundamentals of financial mathematics, it remains synthetic and does not get lost in unnecessary mathematical details that obscure the understanding of the basic concepts. The copula theory to model multivariate dependence structure between variables is also presented. This approach has become popular in finance to price "correlation 
products", that is, derivative structures whose underlying is a basket of assets such as first-to-default credit derivatives or single tranche CLOs. A detailed section on model calibration issues and the associated linear and non-linear optimization techniques complete the chapter. Appendix B provides a large review of the Monte Carlo simulation techniques with a detailed presentation of variance reduction techniques, the extension to the pricing of American Monte Carlo options and practical issues related to the derivation of the Greeks. Appendix C describes tree-based and partial differential equations (PDEs) methods, which are of great use for Bermudan and American options.

To the reader: Learn and enjoy.

\author{
Bernard Lapeyre \\ Ecole Nationale des Ponts \\ et Chaussées
}




\section{ABOUT THE AUTHORS}

Eric Benhamou is the CEO of Pricing Partners. Prior to this, he headed the fixed income quantitative research team at Ixis-CIB, in charge of the modeling for fixed income, inflation, FX hybrids, and funds derivatives for Europe and Asia. Previously he worked for Goldman Sachs on hybrids derivatives, mixing equities, fixed income, funds, FX and commodities. A former alumnus of the Ecole Polytechnique and the French National School of Statistics (ENSAE), he holds a PhD in Financial Mathematics from the London School of Economics and a DEA in Stochastic Calculus from University Paris VI, headed by Nicole El Karoui. He is a regular speaker at Risk conferences and has published various articles on subjects such as advanced Monte Carlo techniques with Malliavin calculus, inflation derivatives, and convexity correction computation.

René Anger is a founding member of Pricing Partners and is currently the Chief Technology Officer. After graduating from Université de Technologie de Compiègne (UTC), he started working for Sungard Infinity, a startup at that time, specialized in Front to Back systems for Interest Rates Derivatives, and worked as an IT consultant in various financial institutions around the world. Prior to joining Pricing Partners, he founded a consulting company specialized in financial markets and worked for various French banks on projects related to pricing, sensitivity calculation, IAS and EAI. René has developed an 
IT system expertise on technologies like generic pricing, grid computing and application service providing applied techniques to the financial field.

Nabyl Belgrade is working in Natexis BP as a front office quant. Prior to that, he worked on inflation quantitative modeling for IxisCIB. He holds a PhD in Financial Mathematics and a DE in Stochastic Calculus from Paris1 Pantheon-Sorbonne University. His main works are on inflation derivatives: valuation of inflation swap, floors swaptions and hybrid options on forward real yield, seasonality estimation and impact in the pricing of the inflation derivatives. He is also an engineer in Statistics applied in Economy and worked previously on the analysis of the American oil and gas market.

Marian Ciucă is currently a quantitative engineer in Pricing Partners. Marian Ciucă graduated from University of Bucharest (Romania) and holds a PhD in Financial Mathematics from the AixMarseille University (France) and a DEA in Applied Mathematics. Prior to joining Pricing Partners, he was a member of the MATHFI research group, from French National Institute for Research in Computer Science and Control (INRIA), where he developed credit derivatives models for their pricer called PREMIA. PREMIA is developed by the MATHFI team in interaction with a consortium of institutions like Société Générale, Calyon, Ixis-CIB, the Crédit Industriel et Commercial (CIC), Summit Systems, EDF and GDF.

Olivier Croissant is currently a senior member of the fixed income quantitative research team at Ixis-CIB. He graduated from Ecole Polytechnique (France) and holds a post-graduate degree in theoretical physics. Prior to joining Ixis-CIB, he was principal mathematician and director of risk projects at Algorithmics, where he developed credit and commodity derivatives pricing functions for risk calculations. Olivier was previously director of financial engineering at Renaissance Software, a company later acquired by Sungard, focusing on fixed income and equity derivatives risk computations. Before starting his financial career in at CIC bank in Paris on an equity derivative desk, he developed expert systems tools in an artificial intelligence company in Monaco and Palo-Alto (California). 
Mostafa Ezzine is currently working for Ixis-CIB in Tokyo in trading and structuring. Prior to that Mostafa worked in the Ixis-CIB's fixed income quantitative team in Paris and previously in Calyon.

Noufel Frikha, graduated from the Ecole Nationale Supérieure d' Informatique et de Mathématiques Appliquées (ENSIMAG), is currently a quantitative engineer in Pricing Partners, working on credit derivatives.

Richard Guillemot is currently a member of the fixed income quantitative research team at Ixis-CIB. A former alumni of Ecole des Mines de Nantes, Richard holds two DEAs, one in computing and one in stochastic calculus. Prior to Ixis-CIB, Richard worked for Calyon.

Othman Kabbaj is currently working in the marketing department of Pricing Partners. He has graduated from the Hautes Etudes Commerciales (HEC) school and is expected to join Lehman Brothers in the sales team.

Yosr Khlif is currently a member of the fixed income quantitative research team at Ixis-CIB. Prior to her role at Ixis-CIB, Yosr worked at Calyon in the risk validation group. Yosr holds a $\mathrm{PhD}$ in Mathematics.

Etienne Koehler is currently the Global head of Quantitative Risk Analysis at Natexis BP. Prior to this role, he has been the global head of quantitative research at Ixis-CIB, Crédit Agricole, Crédit Lyonnais. Associate professor in the University of La Sorbonne and $\mathrm{PhD}$ students' supervisor, Etienne is a former alumnus of Ecole Normale Supérieure. He holds an "Aggregation of Mathematics", a DEA of Mathematics and an MBA of INSEAD. He has published various articles including some in Risk magazine and co-author of several books. He is a regular speaker at quantitative finance conferences.

Leila Korbosli is currently a quantitative engineer in Pricing Partners working on equity derivatives and fixed income equity hybrids. She graduated from the Ecole Nationale Supérieure d' Informatique et de Mathématiques Appliquées (ENSIMAG).

Mohammed Miri is currently a quantitative engineer in Pricing Partners, working on fixed income derivatives. He has graduated from 
the Ecole Nationale Supérieure d' Informatique et de Mathématiques Appliquées (ENSIMAG).

Jean Marc Prié is currently heading the fixed income quantitative research team at Ixis-CIB. He has an extensive knowledge in developing models and worked for various banks including Crédit Lyonnais, Crédit Agricole. Jean Marc Prié holds a degree from Ecole Centrale de Paris and gives regularly lectures in various DEA and Grandes Ecoles courses.

Arnaud Schauly is currently working for Deutsche Bank in the fixed income quantitative research team. Prior to that, he worked at Ixis-CIB. A former alumnus of Ecole Centrale de Paris, he holds a DEA in Financial Mathematics from Dauphine University.

Amine Triki is currently a member of the FX quantitative team at UBS. Prior to that, he worked in the income quantitative research team at Ixis-CIB. A former alumnus of Ecole Des Mines de Paris, he holds a DEA in Stochastic Calculus. 


\section{CONTENTS}

PREFACE $\quad \mathrm{V}$

ABOUT THE AUTHORS ix

1. STANDARD PRODUCTS AND MARKETS 1

1.1. Introduction to Financial Markets . . . . . . . . . . 1

1.1.1. Definition of financial markets . . . . . . . 1

1.1.2. The different derivatives markets . . . . . . 2

1.1.3. Importance of the derivatives . . . . . . . . . 3

1.1.4. Cash or spot vs. derivatives markets . . . . 5

1.1.5. History of financial markets . . . . . . . . 6

1.1.6. Listed markets vs. OTC markets . . . . . . 8

1.1.7. Shares and dividends . . . . . . . . . . 8

1.1.8. Typology of the markets participants . . . . 10

1.2. Presentation of the Trading Room and Group

Description . . . . . . . . . . . 11

1.2.1. Different functionality of the trading room . 11

1.2.2. Job description . . . . . . . . . . . . . . . . . 11

1.2.2.1. Trader . . . . . . . . . . . 11

1.2.2.2. Sales/originators/structurors . . . . 12

1.2.2.3. Quant/IT/analyst support . . . . . 12

1.2.2.4. Middle office/back office support . 12

1.3. Flow Business, Prop Trading and Exotic . . . . . . 13 
1.3.1. Definition . . . . . . . . . . . . . . . 13

1.3.2. Hedge fund business . . . . . . . . . . . . . . . . 13

1.3.3. Key differences . . . . . . . . . . . . . . . . . . . . 13

1.3.4. Market making . . . . . . . . . . . . . 14

1.3.5. ECN and electronic trading platform . . . . 14

1.4. Ethic and Deontology . . . . . . . . . . 15

1.4.1. History . . . . . . . . . . . . 15

1.4.1.1. Barings . . . . . . . . . . 15

1.4.1.2. ENRON . . . . . . . . . . 16

1.4.1.3. LTCM . . . . . . . . . . . . . 17

1.4.2. Insider trading . . . . . . . . . . . . . . . . . . . . . . . . 18

1.4.3. Money laundering . . . . . . . . . . . . . . . . . 19

1.5. Summary . . . . . . . . . . . . . . . . . . . . . . . . . . . . 19

References ................ 20

2. THE VANILLA PRODUCTS 21

2.1. Interest and Usage of Products . . . . . . . . . . 22

2.1.1. Interest and usage of products . . . . . . . . 22

2.1.2. Derivatives description . . . . . . . . . . . 22

2.1.3. The hedging purpose . . . . . . . . . 23

2.1.3.1. Hedging with forward contract . . . 23

2.1.3.2. Hedging with options . . . . . . . 24

2.1.4. The speculation . . . . . . . . . . . . . . . . 25

2.1.5. The arbitrage . . . . . . . . . . . . . . . . 26

2.2. Pricing of Future Contract . . . . . . . . . . 27

2.2.1. Trading futures: Margin call and trading account .............. 27

2.2.1.1. The future contract . . . . . . . . 27

2.2.1.2. Product specification . . . . . . . 28

2.2.2. Futures vs. forward . . . . . . . . . . 30

2.2.3. Forward and futures prices . . . . . . . . . 30

2.2.3.1. Forward pricing . . . . . . . . 30

2.2.3.2. Futures prices . . . . . . . . 31

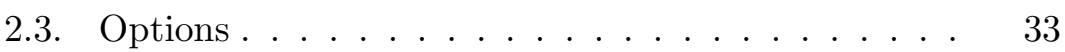

2.3.1. Definition and features . . . . . . . . . . 33

2.3.2. Call-put parity . . . . . . . . . 35 
2.3.3. Option strategies: call, put, straddle, strangle, spread and butterfly . . . . . . 35

2.3.3.1. Call/put option . . . . . . . 36

2.3.3.2. Straddle . . . . . . . . . . . 37

2.3.3.3. Strangle . . . . . . . . . . . 38

2.3.3.4. Butterfly . . . . . . . . . 39

2.3.4. Warrants ............. . 40

2.4. Summary . . . . . . . . . . . . . . 41

References ................ 42

3. INTRODUCTION TO FINANCIAL MODELING 43

3.1. A Bit of History . . . . . . . . . . . . . . . 43

3.2. Usage of Models . . . . . . . . . . . . . . . 48

3.2.1. Risk categories . . . . . . . . . . . 48

3.2.1.1. Market risk . . . . . . . . . . . . . 48

3.2.1.2. Counterparty risk . . . . . . . . . 50

3.2.1.3. Operational risk . . . . . . . . . 50

3.2.1.4. Model risk . . . . . . . . . . 52

3.2.2. What are models for? . . . . . . . . . 53

3.2.2.1. As a predictor . . . . . . . . 53

3.2.2.2. As an "interpolator" or "extrapolator" ......... . 53

3.2.3. Simple versus complicated models . . . . . . 55

3.2.4. Warnings . . . . . . . . . . . 56

3.2.5. Special warnings: calibration issues . . . . . 58

3.3. Reasonable Mathematical Basis for Financial

Modeling . . . . . . . . . . . 59

3.3.1. Modeling framework . . . . . . . . . . 59

3.3.1.1. Words on probability . . . . . . 60

3.3.1.2. Types of computations . . . . . . 61

3.3.1.3. Ito processes and Ito/Doblin formula ........... 62

3.3.1.4. Usage of Brownian motion . . . . . 64

3.3.2. Risk neutral probability . . . . . . . . . 67

3.3.2.1. Example of the one factor case . . . 67

3.3.2.2. The $n$ factor case . . . . . . . . . 69 
3.3.2.3. The two currency case . . . . . . . 73

3.4. Summary . . . . . . . . . . . . . . . 77

References .................. 78

4. THE BLACK-SCHOLES MODEL 79

4.1. Model History . . . . . . . . . . . . . . . . . . 79

4.2. Initial Problems . . . . . . . . . . . . . . . . . . . 80

4.3. Model Hypothesis . . . . . . . . . . . . . . 82

4.3.1. Lognormal distribution and constant volatility . . . . . . . . . . 82

4.3.2. Assumptions . . . . . . . . . . . . . . . . 82

4.4. Black-Scholes Partial Differential Equation . . . . . 83

4.5. Black-Scholes Formulae for Call and Put Options . 85

4.6. Implied Volatility and Smile . . . . . . . . . . 86

4.7. Hedging Strategies . . . . . . . . . . . . . . 86

4.7.1. Naked and cover positions . . . . . . . . 87

4.7.2. Delta hedging . . . . . . . . . . . . . . 87

4.7.3. Stop and loss strategy . . . . . . . . . 87

4.8. The Derivative Function of the Price or Greeks . . 90

4.8.1. Delta . . . . . . . . . . . . 90

4.8.2. Theta . . . . . . . . . . . . 91

4.8.3. Gamma . . . . . . . . . . . . . . . . . . 92

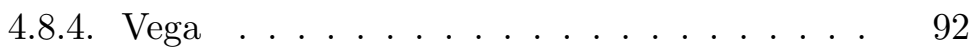

4.9. Black-Scholes Robustness . . . . . . . . . . . . 94

4.10. Black-Scholes Extensions . . . . . . . . . . . 95

4.10.1. Volatility: deterministic function of time . . 95

4.10.2. Dividend . . . . . . . . . . . 95

4.10.3. Normal and shifted lognormal models . . . 96

4.11. Summary . . . . . . . . . . . . . . . . . . . . . . 97

References .................... 98

5. FIXED INCOME BASIS 99

5.1 Simple Instruments . . . . . . . . . . . . . . . . . . . 99

5.1.1. Markets conventions . . . . . . . . . . . 99

5.1.2. LIBOR rates . . . . . . . . . . . . . . . . . . . . . . . . . . . 100

5.1.3. Repo rate. . . . . . . . . . . . . 101 
5.1.4. Duration . . . . . . . . . . . 102

5.2 Bootstrapping and Curve Fitting . . . . . . . . . . 104

5.3 Introduction to Swaps . . . . . . . . . . . 105

5.3.1. Vanilla swaps . . . . . . . . . . . . . . . . 105

5.3.2. Cross-currency swaps . . . . . . . . . . . . 106

5.3.3. Forward starting swaps . . . . . . . . . . . . . . 109

5.3.4. LIBOR-in-arrears swaps . . . . . . . . . . . . 110

5.3.5. CMT and CMS swaps . . . . . . . . . . . . . . . 110

5.4 Convexity Adjustment . . . . . . . . . . . . . 111

5.4.1. Convexity correction . . . . . . . . . . . 111

5.4.2. LIBOR-in-arrears swap . . . . . . . . . . . . . . . 112

5.4.3. CMS/CMT/spread lock . . . . . . . . . . 114

5.4.4. Replication . . . . . . . . . . . . . . 116

5.5 Vanilla Interest Rate Options . . . . . . . . . . 120

5.5.1. Interest rate caps and floors . . . . . . . . . . . 120

5.5.2. European swaptions . . . . . . . . . . . . . . . . . 122

5.5.3. Spread options . . . . . . . . . . . . . . . . . . 123

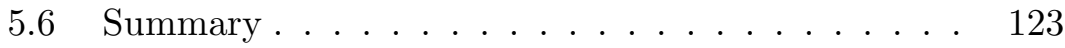

References .................. 124

6. SMILE MODELING 125

6.1. Smile and Digital Models . . . . . . . . . . . 125

6.1.1. Target market . . . . . . . . . . . 126

6.2. Smile Models (Basic European Models) . . . . . . . 127

6.2.1. The Merton model . . . . . . . . . . . . . 128

6.2.1.1. Influence of the jumps (a la Merton) on the smile . . . . . . . . . 129

6.2.2. Local volatility models (a la Dupire) . . . . . 129

6.2.3. The CEV model . . . . . . . . . . . . . . 131

6.2.3.1. Extrapolation issues. . . . . . . . 133

6.2.3.2. Robustness issues . . . . . . . . . . 133

6.2.4. Stochastic volatility models . . . . . . . . . 134

6.2.4.1. An analytical formula . . . . . . . 135

6.2.4.2. Heston model and Fourier transform . . . . . . . 136 
6.2.4.3. Lewis model and the preservative approach . . . . . . . . 136

6.2.4.4. SABR model and link to Riemannian geometry . . . . . . . 138

6.2.5. Connection between the SABR and the "complex" BS models . . . . . . . . . . . . . 142

6.2.5.1. Expected local time and vanilla option prices . . . . . . . . . . 142

6.2.5.2. Expected local time and probability density . . . . . . . . . . . 144

6.2.5.3. Explicit computation of the local time for stochastic models . . . . 145

6.2.5.4. Fast computation of the SABR stochastic integral and connection with BS model . . . . . . . . . . 146

6.2.5.5. Application to CMS replication pricing . . . . . . . . . . . 148

6.2.6. Volatility and variance swap: $\log$ and parabola contracts . . . . . . . . . . . . 152

6.2.6.1. Contract definition . . . . . . . . . 152

6.2.6.2. Replication strategy and pricing . . 153

6.2.6.3. Variance swap in the Heston model ... . . . . . . . . . 154

6.2.6.4. Variance swap in the mean reverting lognormal model . . . . . 154

6.2.6.5. Application 1: Computation of expected volatility . . . . . . . 155

6.2.6.6. Application 2: Computation of the variance call . . . . . . . 156

6.3. Summary . . . . . . . . . . . . . . 156

References .................. 157

7. YIELD CURVE MODELING 159

7.1. Model Typology . . . . . . . . . . . . . . . . 159

7.1.1. Short rates . . . . . . . . . . . 159

7.1.2. Market (LIBOR and swap rate) models . . . 160

7.1.3. Markov functional models . . . . . . . . . 161 
7.2. Heath-Jarrow-Morton Framework . . . . . . . . . . 163

7.2.1. Philosophy . . . . . . . . . . . . . . . 163

7.2.2. Forward bond volatility and drift . . . . . 164

7.3. Short Rate Models . . . . . . . . . . . . . . . . . 165

7.3.1. HW $1,2, \ldots, \mathrm{nF} \ldots \ldots \ldots \ldots \ldots \ldots$

7.3.1.1. Diffusion equation . . . . . . . . . 165

7.3.1.2. Model's calibration . . . . . . . . 167

7.3.1.3. Pricing of caplets . . . . . . . . . 167

7.3.1.4. Pricing of swaptions . . . . . . . . . 168

7.3.1.5. Example of calibration of the model . . . . . . . . . . . . 169

7.3.2. Cox-Ingersoll-Ross model . . . . . . . . . . 170

7.3.2.1. Diffusion equation . . . . . . . . . . 170

7.3.2.2. Reconstruction formulae . . . . . 170

7.3.2.3. Remark . . . . . . . . . . . 171

7.3.3. Black-Karasinski model . . . . . . . . . . . . 172

7.3.3.1. Diffusion equation . . . . . . . . . 172

7.3.3.2. Remarks . . . . . . . . . . . 172

7.4. Market Model (BGM) . . . . . . . . . . . . . . 173

7.4.1. Motivations . . . . . . . . . . . . . . 173

7.4.2. Diffusion . . . . . . . . . . . . . 173

7.4.3. Interpolation . . . . . . . . . . . . 175

7.4.4. Handling drift . . . . . . . . . . . . . . 177

7.4.5. Calibration: Relation vol Swap vol Fra . . . 178

7.5. Extension to Smile . . . . . . . . . . . . . . . . . 180

7.5.1. Short-rate model extension and Cheyette . . 180

7.5.1.1. Quadratic Gaussian model . . . . . 180

7.5.1.2. Cheyette model . . . . . . . . . 181

7.5.1.3. Swaption pricing approximation in Cheyette . . . . . . . . . 182

7.5.2. BGM extension: constant elasticity of variance (CEV) (Cox and Ross, 1976), SFRM . . . . . . . . . . . . 183

7.5.3. Stochastic volatility with BGM models ... 184

7.6. Summary . . . . . . . . . . . . . . . . . . . . 184 References . . . . . . . . . . . . . . . 186 
$\begin{array}{ll}\text { 8. INFLATION } & 187\end{array}$

8.1. Vanilla Products . . . . . . . . . . . . . . 187

8.1.1. History of inflation markets . . . . . . . . 187

8.1.2. Swap: YoY, zero coupon and bond . . . . . . 188

8.1.3. Option: Cap, floor and swaption . . . . . . . 189

8.1.4. Pricing example . . . . . . . . . . . . . . . 191

8.2. Vanilla Product Pricing . . . . . . . . . . . . . 192

8.2.1. Presentation . . . . . . . . . . . . 192

8.2.2. Curve modeling . . . . . . . . . . . 193

8.2.3. Convexity adjustment . . . . . . . . . . . 194

8.3. Seasonality . . . . . . . . . . . . . 194

8.3.1. Motivations and static seasonality modeling . . . . . . . . . . . . 194

8.3.2. Parametric estimation of seasonality . . . . 198

8.3.3. Parametric vs. non-parametric . . . . . . 200

8.3.4. Pricing impact on various inflation linked derivatives . . . . . . . . . . 205

8.4. Hybrid model . . . . . . . . . . . . . . 207

8.4.1. Jarrow-Yildirim model . . . . . . . . . . 207

8.4.2. Mercurio model . . . . . . . . . . . . . 210

8.4.3. Market model . . . . . . . . . . . . . . . 213

8.4.4. Index equity model . . . . . . . . . . . . . . . . . 218

8.5. Summary . . . . . . . . . . . . . . . . 219

References ....................... 219

9. HYBRID MODELS 221

9.1. Basis Hybrid . . . . . . . . . . . . . . . 221

9.1.1. Bermuda option . . . . . . . . . . . 222

9.1.2. Model . . . . . . . . . . . . . . . 222

9.1.2.1. Forward forex rate . . . . . . . . 222

9.1.2.2. Basis margin . . . . . . . . . . . . . 225

9.2. Forex Hybrids . . . . . . . . . . . . . . . 226

9.2.1. Market, products and models . . . . . . . 226

9.2.2. Short rates model . . . . . . . . . . . . 228

9.2.2.1. Theoretical model . . . . . . . . 228 
9.2.2.2. Underlying future price . . . . . . . 229

9.2.2.3. Implementation details . . . . . . . 230

9.2.2.4. Basis curves . . . . . . . . . . . 232

9.2.2.5. Smile issue . . . . . . . . . . . . . . 233

9.2.3. LIBOR market model . . . . . . . . . . . . 235

9.2.3.1. Diffusion overview . . . . . . . . 235

9.2.3.2. Pricing method . . . . . . . . 236

9.2.4. Equity hybrids . . . . . . . . . . . . . 237

9.2.5. Credit hybrids . . . . . . . . . . . . 238

9.2.6. Alternative structured products . . . . . . . 240

9.3. Summary . . . . . . . . . . . . . . . . . . 240

References .................. 241

10. PRODUCT CATALOG AND USAGE 243

10.1. Typology . . . . . . . . . . . . . 243

10.1.1. Investment vs. hedging . . . . . . . . . . 243

10.1.2. Investment products: high-risk products . 245

10.1.2.1. High-coupon strategy . . . . . . 245

10.1.2.2. Yield curve slope strategy _. . 245

10.1.2.3. Callability . . . . . . . . . 245

10.1.2.4. Bet strategy: corridor and digital .......... 245

10.1.2.5. Quanto strategy . . . . . . . 245

10.1.2.6. Currency convergence trade . . 246

10.1.2.7. Hedging products: low premium .......... 246

10.1.2.8. Zero-premium strategy . . . . . 246

10.1.2.9. Customized products . . . . . . 247

10.1.2.10. Barrier options . . . . . . . . . 247

10.1.3. Product typology . . . . . . . . . . . 248

10.2. Products Catalog . . . . . . . . . . . . . . . . 248

10.2.1. European options . . . . . . . . . . . . . 248

10.2.2. Asian options . . . . . . . . . . . . . . 250

10.2.3. Hawaiian options . . . . . . . . . . . 253

10.2.4. Barrier options . . . . . . . . . 253

10.2.5. Lookback and extensions . . . . . . . . 254 
10.2.6. PNL and passport options . . . . . . . . 254

10.2.7. Simple correlation/multi-asset options . . 255

10.2.8. Option on options . . . . . . . . . . 256

10.2.9. Chooser options . . . . . . . . . . 256

10.3. Equity Derivatives . . . . . . . . . . . . 257

10.3.1. Complex correlation/multi-asset options . 257

10.4. Exotic Interest Rates Products . . . . . . . . . . . 262

10.4.1. Averaging amortizing compounding/ accreting swap . . . . . . . . . . . 262

10.4.2. Autocap, chooser cap, flexi cap . . . . . . 262

10.4.3. Callable reverse floater . . . . . . . . 263

10.4.4. Target redemption note (TARN) . . . . . 264

10.4.5. Callable snowball . . . . . . . . . . . 270

10.4.6. Callable spread options . . . . . . . . . . 273

10.4.7. New types of underlying and options . . . 273

10.4.8. Management of a trading book . . . . . . 273

10.4.9. Risk class . . . . . . . . . . . . 274

10.4.9.1. Interest rate risk . . . . . . . 274

10.4.9.2. Volatility risk . . . . . . . 274

10.4.9.3. Basis risk . . . . . . . . . . 274

10.4.9.4. Smile ........... . . . 274

10.4.9.5. Correlation . . . . . . . . . 275

10.4.9.6. Foreign exchange . . . . . . . . 275

10.4.10. Risk management . . . . . . . . . . . 275

10.4.10.1. Delta, Gamma, Vega hedging . 276

10.4.11. PNL explanations (Greeks) . . . . . . . 276

10.5. Summary . . . . . . . . . . . . . . . . . . 276

References .................. 276

11. THIRD GENERATION TRADING

SYSTEM AND ITS UNDERMINING

COPERNICAN REVOLUTION 279

11.1. The New Generation of Trading Systems . . . . . . 279

11.2. Motivation for a Generic Pricer . . . . . . . . . 281

11.2.1. Product innovation . . . . . . . . . . 281

11.2.2. Reactivity, flexibility and efficiency . . . . 282 
11.2.3. Maintenance and evolution . . . . . . . . 283

11.2.4. Front to back, enterprise wide . . . . . . . 283

11.3. Example of an Architecture . . . . . . . . . . . . . 284

11.3.1. Price-it ${ }^{\circledR}$, the Pricing Partners' generic pricer solution . . . . . . . . . . . . . 284

11.3.2. Cash flows vs. events . . . . . . . . . 285

11.3.3. Decomposition: security, model and numerical methods . . . . . . . . . . . 286

11.3.4. Critical tasks for a generic pricer . . . . . 287

11.3.5. Parsing system and financial language . . 288

11.3.5.1. Interest of a meta language . . . 288

11.3.5.2. Description of the cash flows with a meta language . . . . . . 288

11.3.5.3. Referencing ......... . 292

11.3.5.4. Components of the meta language: Functions and operators . . . . . . . . 293

11.3.5.5. Standard programming operators . . . . . . . . . 294

11.3.5.6. Financial operators . . . . . . . 294

11.3.5.7. Parsing the grammar and creating a syntax . . . . . 296

11.3.5.8. Example of table of cash flows in a meta language . . . . . . 298

11.3.5.9. Split between models and numerical methods . . . . . . 299

11.3.5.10. Generic code and design . . . . 300

11.3.5.11. Split between models and calibration ......... 300

A. TECHNICAL TOOLBOX 303

A.1. Stochastic Calculus . . . . . . . . . . . . . 303

A.1.1. Itô formula . . . . . . . . . . . . 303

A.1.2. Girsanov theorem . . . . . . . . . . . . . 304

A.1.3. Feynman-Kac . . . . . . . . . . . 305

A.1.4. Tanaka and local time ........ 307 
A.1.5. Markov property ........... 309

A.1.6. Risk neutral and numeraire . . . . . . 310

A.1.7. Copula . . . . . . . . . . . . . . . 313

A.2. Econometrics . . . . . . . . . . . 315

A.2.1. Time series . . . . . . . . . 315

A.2.2. GARCH and Nelson result . . . . . . . 316

A.3. Numerical Analysis . . . . . . . . . . . . . . 318

A.3.1. PCA, Cholesky . . . . . . . . . . 318

A.3.2. Minimizing the errors: Newton-Raphson search . . . . . . . . . . 320

A.3.3. Optimizer: BFGS, conjugate and steepest gradient . . . . . . . . . . . 322

A.4. Expansion Technique . . . . . . . . . . . . 326

A.4.1. Perturbation theory . . . . . . . . . 326

A.4.2. Taylor series with Malliavin weights . . . . 327

A.4.3. Singular perturbation and the WKB expansion . . . . . . . . . . . . 328

A.4.4. Spectral expansion . . . . . . . . . . 329

A.4.5. Gram Charlier/Edgeworth . . . . . . . 332

A.4.5.1. Cumulants . . . . . . . . 332

A.4.5.2. The cumulant modifying operator $(\mathrm{CMO}) \ldots \ldots . . . .333$

A.4.5.3. Application to pricing . . . . . 333

A.5. Summary . . . . . . . . . . . . . 334

References ...................... 335

B. MONTE CARLO 337

B.1. Monte Carlo . . . . . . . . . . . . . . . . . 337

B.1.1. Theoretical background: central limit theorem ............ 337

B.1.2. Pricing European securities using Monte Carlo . . . . . . . . . . . . . . 338

B.1.3. Random numbers and quasi Monte Carlo . 339

B.1.3.1. Box-Muller . . . . . . . . . . 339

B.1.3.2. Cumulated density inverse . . . 339

B.1.4. Notion of discrepancy . . . . . . . . . . . 340 
B.1.5. Examples of random numbers generation . 341 B.1.5.1. The combined MRG of order 5 . 341

B.1.6. Examples of quasi-random numbers generation . . . . . . . . . . . . 342 B.1.6.1. Halton quasi-random sequences . . . . . . . . . 342

B.1.6.2. Square quasi-random sequences . . . . . . . . . 343

B.1.6.3. Sobol sequence . . . . . . . . . . 344

B.1.7. Variance reduction techniques . . . . . . . 344 B.1.7.1. Control variate . . . . . . . . . 344 B.1.7.2. Importance sampling . . . . . . 345 B.1.7.3. Antithetic control . . . . . . . 347 B.1.8. Computation of Greeks in Monte Carlo . . 348 B.1.8.1. Finite differences . . . . . . . . 348 B.1.8.2. Path-wise method . . . . . . . . 349 B.1.8.3. Likelihood ratio method . . . . 350 B.1.8.4. Malliavin calculus . . . . . . . 351 B.1.8.5. Stochastic analysis . . . . . . 351

B.1.9. Extension of Monte Carlo methods for American-style securities pricing . . . . . . 352 B.1.9.1. Andersen method . . . . . . . . 353 B.1.9.2. Longstaff-Schwartz method . . 356

B.2. Summary . . . . . . . . . . . . . 357 References ................ 357

C. TREE AND PDE METHODS 359

C.1. Trees .................. 359

C.1.1. Arrow Debreu prices . . . . . . . . . 359

C.1.2. Computing probabilities in a generated trees . . . . . . . . . . . . . 359

C.1.3. Geometry and boundaries ........ 364

C.1.4. Smoothing . . . . . . . . . . . 366

C.2. Partial Differential Equations . . . . . . . . 366

C.2.1. Motivation . . . . . . . . . . . . 366

C.2.2. Finite difference . . . . . . . . . 368 
xxvi Global Derivatives: Products, Theory and Practice

C.2.3. Crank Nicholson . . . . . . . . . . 370

C.2.4. Stability and robustness . . . . . . . 370

C.2.5. Finite differences schemes for

multi-dimensional PDE: alternating

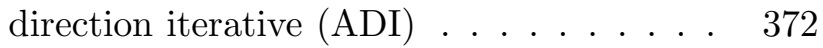

C.2.6. Finite elements . . . . . . . . . . . 376

C.3. Summary . . . . . . . . . . . . . . . . 378

References ................... 378

$\begin{array}{ll}\text { INDEX } & 379\end{array}$ 